\title{
Retrospective Analysis of Clinical Outcome of Intraoperative Epidural Steroid Injection Versus No Steroid Injection after Standard Lumbosacral Discectomy
}

\author{
Suresh Pandey, ${ }^{1}$ Suraj Bidari ${ }^{2}$ \\ ${ }^{1}$ Department of Orthopedics, College of Medical Sciences, Bharatpur-10, Chitwan, Nepal.
}

\begin{abstract}
Background: Despite operative decompression of neural structure with discectomy in the indicated cases of lumbosacral disc herniation, many patients continue to experience back pain and leg pain in the postoperative period. Use of intraoperative local epidural steroid injection has been in practice to reduce this complications but there are concern and controversies regarding its benefit and risk. So this study aims to analyze clinical outcome in terms of reduction in pain, hospital stay, postoperative use of analgesics and risk associated with the use of intraoperative epidural steroid locally and comparison to those who did not receive steroid.
\end{abstract}

\begin{abstract}
Methods: This was a retrospective analysis of total of 44 patients, 28 patients who received Epidural Steroid Injection (ESI) locally after lumbosacral standard discectomy and comparison of the outcome with results of 16 patients with standard lumbosacral discectomy who did not receive ESI. Outcome measurement was done between two groups in terms of postoperative pain VAS scale, use of analgesics, hospital stay and complications if any.

Results: There were total of 44 cases ( 28 steroid group and 16 no steroid group) with mean age of 39.93 years, male 27 and female 17 who underwent standard discectomy and followed up for at least one year. Overall, preoperative mean VAS score for pain improved from 7.95 to 1.55 at 1 year after operation which was significant $p<0.05$. On comparison of 24 hour postoperative VAS score and hospital stay between the groups with steroid and no steroid, it was mean of 5.32 versus 6 and 4.43 days versus 5.25 days $(\mathrm{p}<0.05)$ respectively which was significant. All the patients in no steroid group needed both NSAID and opioids for the postoperative pain management whereas only $12(42.8 \%)$ patient needed addition of opioids in steroid group. There was no difference in VAS score at 1 week and 1 year. There was no complications in either of the group.
\end{abstract}

Conclusions: Use of intraoperative ESI help to reduce early postoperative pain, hospital stay and use of opioids without adding further risk or complication.

Keywords: discectomy; epidural steroid injection; postoperative pain.

\section{INTRODUCTION}

Disc herniation in the lumbosacral region is the commonest cause of back pain with radiculopathy in the leg. Majority of them can be treated successfully with conservative treatment but $10 \%$ of them who fail to respond to nonoperative treatment may need operative decompression to relieve the pressure on the nerve root. Causes of pain in herniation of nucleus pulposus are mechanical compression and release of chemical mediators from herniated disc. So, despite discectomy to relieve the mechanical pressure, many patients continue to complain pain over the back and leg due to irritation by chemical mediators during postoperative period. ${ }^{1}$

Use of intraoperative local epidural steroid injection (ESI) after discectomy has been in use for more than 3 decades to relieve the postoperative pain.
Though, its role has been controversial, many studies have shown decreased postoperative pain, improved visual analog pain scale (VAS), decreased need of postoperative analgesia and decreased hospital stay. Its role is to reduce the inflammation around the neural tissue and also have role in decreasing fibrosis. ${ }^{2}$ Some studies have shown concern for slight increase in infection in the cases with intraoperative steroids injection, this has not been documented significant. Akinduro et al. in his study of outcome of lumbosacral discectomy has shown better postoperative pain relief, less use of opioids and decreased hospital stay among the patients who received epidural steroid injection (ESI) with slight increased tendency of infection which was not significant. ${ }^{3}$ Cenic et al. in his study found that $49 \%$ of Canadian spine surgeons use epidural steroids after lumbar discectomy.

Correspondence: Dr. Suresh Pandey, Department of Orthopedics, College of Medical Sciences, Bharatpur10, Chitwan, Nepal. Email: drsuresh.orthonepal@gmail.com. Phone: +977-9845047228. Article received: 2019-05-21. Article accepted: 2019-11-25. 
This is retrospective analysis of clinical outcome of standard discectomy in lumbosacral disc herniation in indicated cases with comparison between two groups, local ESI use before closure after discectomy to no use of steroid.

\section{METHODS}

This is a retrospective analysis of functional outcome of standard open discectomy of lumbosacral disc herniation in 44 patients with or without ESI for a period of three years with minimum follow up of 1 year. Data was extracted from hospital admission and operative charts and follow up with direct examinations of patients and further questionnaires. They were operated after adequate trial of conservative treatment. Indications for operations were disabling leg pain with or without back pain with failure of adequate trial of conservative treatment. Diagnosis was based on the clinical history and examination and correlation and confirmation with MRI findings. Inclusion criteria were patient with acute or chronic moderate to severe back pain with radiculopathy with or without sensory and motor impairment with failure of conservative treatment in the age group 25-55 years. Exclusion criteria was patient with previous history of back operation in the same level, evidence of spinal infection, tumor or fracture, evidence of instability and back pain only.

Demographic data was collected including prior treatment, use of prior epidural steroid injection, physiotherapy, sensory, motor weakness, operative details, postoperative pain VAS score at 24 hour, 1 week and one year. Any complications intraoperative or postoperative were noted. Use of analgesics/ opioids and hospital stay were recorded and difference was analyzed between patients who received intraoperative ESI and patients who did not receive.

\section{Operative Details}

All the patients were operated by single surgeon from the period of January 2015 to December 2018 having suitable indications under general anaesthesia under prone position. Prophylactic antibiotics was given 1 hour prior to incision. Patient was positioned in Jack knife like or knee chest position. Painting and draping was done. Incision was marked under the $\mathrm{C}$ arm control and 2 inch midline skin incision at the affected level was made. Skin, subcutaneuous tissue and fascia was divided along the line of incision and muscle on the decompression side only erased subperiosteally up to level of facet joint. Level was again confirmed with marker in the interlaminar space and ligamentum flavum was opened. Partial laminotomy of the inferior margin of superior lamina and superior margin of inferior lamina was done to expose dura and nerve root. Dura and nerve root were retracted medially, protruded or extruded disc was identified and removed with pituitary rongeur. Adequacy of decompression was checked and thorough lavage was done. $40 \mathrm{mg}$ of injection Triamcinolone was spreaded around the nerve root, dura and disc space after discectomy just before closure. No fat pad was applied over the exposed dura or nerve root. Wound was closed in layer and dressing was done.

\section{Postoperative care and Follow up}

Patient was managed with NSAID only and opioid was added as per the need in steroid group whereas regular injectable NSAIDs and Opioids as per the need among non steroidal group. VAS score was used to assess pain at 24 hour, 1 week and 1 year after operation and compared between two groups and also to preoperative VAS score.. Mobilization and walking was permitted next day onward. Physiotherapy with spine core muscle exercise was started on 1st postoperative day and it was continued at least 3 months. Complications, if any were noted and compared between two groups. Oswestry Disability Index (ODI) was measured and compared between two groups. ODI score involves questionnaires in 10 fields related to pain and its effect on disability in daily life. They are pain intensity, personal care, lifting, walking, sitting, standing, sleeping, sex life, social life and travelling. Score ranges from 0 as no pain to 5 as maximum disability. Total score is calculated in percentage by adding total score obtained by maximal score i.e. 50 and multiplying it by 100 . Result was also graded as per Macnab criteria at 1 year after the operation as per following observation. So $0 \%$ indicates no pain and no disability to $100 \%$ indicating maximum pain and maximum disability.

\section{Macnab Criteria}

Excellent: No pain and no restriction of activity

Good: Occasional pain but no need of restriction or modification of activity

Fair: Some improvement but needs medications and restriction of activities

Poor: No improvement or worsening and need further operative intervention

Data were entered in Excel software and analysis was done using SPSS 20 software. Level of significance was set to $<0.05$.

\section{RESULTS}

There were total of 44 cases of lumbosacral disc herniation of varying grade operated in the period of three years by a single surgeon and clinical result was analyzed with minimum follow up of 1 year. There were $27(62.4 \%)$ male and $17(38.6 \%)$ female with average age of 39.93 years, ranged from $32-58$ years. Total $28(63.6 \%)$ patients 
received ESI and $16(36.4 \%)$ did not. Table 1 shows the basic demographic data and Table 2 shows the comparison in both the steroid and no steroid group. $\mathrm{P}$ value was $>0.05$ in all the group indicating that subjects in the both the groups were similar.

\begin{tabular}{|lc|}
\hline $\begin{array}{l}\text { Table 1. Showing demographic } \\
\text { parameters. ODI=Oswestry }\end{array}$ & $\begin{array}{c}\text { and preoperative } \\
\text { Disability }\end{array}$ \\
VAS=Visual Analogue Scale. & \\
\hline Index, & \\
\hline Particulars & Mean \\
Age (yrs) & 38.43 \\
Sex (male:female) & $27: 17$ \\
Mean Duration of symtoms (wks) & 12.98 \\
Preop pain mean VAS & 7.95 \\
ODI preop & 76.8636 \\
Extrusion n(\%) & $38(86.4)$ \\
Protrusion & $4(9.1)$ \\
Sequestration & $2(4.5)$ \\
\hline
\end{tabular}

The majority of cases were disc extrusion $38(86 \%)$ followed by protrusion and sequestration. The baseline characteristics were similar and comparable in both the groups. Mean operative time for standard discectomy was 93 minute (range 75-120) and average blood loss in the operation was $136 \mathrm{ml}$.

\begin{tabular}{|c|c|c|}
\hline \begin{tabular}{|lr} 
Table 2. & Shon \\
comparison betwee
\end{tabular} & $\begin{array}{lr}\text { ving } & \text { preoperativ } \\
\text { en steroid and no st }\end{array}$ & $\begin{array}{l}\text { paramete } \\
\text { id group. }\end{array}$ \\
\hline Parameters & $\begin{array}{c}\text { Mean local steroid } \\
(n=28) \text { no steroid } \\
(n=16)\end{array}$ & $\begin{array}{l}\text { Standard } \\
\text { Deviation }\end{array}$ \\
\hline Age & $\begin{array}{l}\text { Steroid } 37.21 \\
\text { No steroid } 40.56\end{array}$ & $\begin{array}{l}14.255 \\
10.551\end{array}$ \\
\hline Symptom Duration & Steroid 13.32 & 8.803 \\
\hline $\begin{array}{l}\text { Preop Back pain } \\
\text { VAS score }\end{array}$ & $\begin{array}{l}\text { Steroid } 7.96 \\
\text { No steroid } 7.94\end{array}$ & $\begin{array}{l}.838 \\
.929\end{array}$ \\
\hline ODI preop & $\begin{array}{l}\text { Steroid } 76.7857 \\
\text { No steroid } 77.0000\end{array}$ & $\begin{array}{l}6.28553 \\
5.79655\end{array}$ \\
\hline
\end{tabular}

Overall, mean VAS score for pain improved from preoperative 7.95 to 1.55 at 1 year after operation which was significant $p<0.05$. On comparison of 24 hour postoperative VAS score and hospital stay between the groups with steroid and no steroid, it was mean of 5.32 vs 6 and 4.43 vs 5.25 days respectively which were statistically significant.

Table 3. Showing outcome measurement about hospital stay, ODI and pain scale between steroid and no steroid group.

\begin{tabular}{|c|c|c|c|}
\hline Measurement & $\begin{array}{c}\text { Steroid }(n=28) \\
\text { no steroid }(n=16)\end{array}$ & Mean & $\overline{\text { P value }}$ \\
\hline \multirow[b]{2}{*}{ Hospital stay } & Steroid & 4.43 & .017 \\
\hline & No steroid & 5.25 & \\
\hline \multirow[b]{2}{*}{ ODI at 1 year } & Steroid & 42.14 & .618 \\
\hline & No steroid & 45.50 & \\
\hline \multirow{2}{*}{ VAS $24 \mathrm{hr}$} & Steroid & 5.32 & .027 \\
\hline & No steroid & 6.00 & \\
\hline \multirow{2}{*}{ VAS 1wk } & Steroid & 3.00 & .775 \\
\hline & No steroid & 4.25 & \\
\hline \multirow{2}{*}{ VAS 1 year } & Steroid & 1.46 & .379 \\
\hline & No steroid & 1.69 & \\
\hline
\end{tabular}

But there was no significant difference between pain score at 7 days, one year and ODI score between the two groups.

There were 15 (53.5\%) cases in steroid group who were managed with NSAID only during postoperative period whereas 13 (46.5) needed addition of opioids in the postoperative pain management. On the opposite hand, all 16 patients in the no steroid group needed NSAID and opioids for the postoperative pain management. Overall, mean ODI score together improved from preoperative 76.86 to 43.36 at one year after operation. According to Macnab criteria, there were $96 \%$ good to excellent, $4 \%$ fair result in steroid group as compared to $88 \%$ good to excellent and $12 \%$ fair in no steroid group. There was no postoperative infection, recurrence, dural tear, neurological deficit or repeat operation in any patient in either group.

\section{DISCUSSION}

This retrospective analysis of clinical results in patients with standard discectomy with or without ESI intraoperatively has shown short term postoperative benefit in terms of better pain relief, less use of analgesics and shorter hospital stay among the steroid group. But the previous studies including randomized controlled trial and meta-analysis have shown variable results. ${ }^{5,6}$ Postoperative back pain and even persistent radiculopathy after discectomy is common problem after discectomy in many patients. It is an unsolved mystery both for patient and operating surgeon contrary to what is normally expected after decompression of neural structure. It carries bad experience to patient, increases hospital stay, cardiorespiratory risk and morbidity. ${ }^{3,4}$ The explanation for such pain despite decompression is due to chemical inflammation from the disc material and handling of neural tissue. 7 Use of intraoperative epidural steroid injection after discectomy has been in practice for more than 3 decades but its role and safety are still debatable among the treating surgeons. Use of local epidural steroid injection before closure is supposed to act by inhibition of local inflammation and reduction of edema.

Analysis of 15 trials published by Jamjoom et al. has shown variable results with majority of the trial showing significant reduction in early postoperative pain among the groups who received ESI intraoperatively. ${ }^{5}$ Akinduro et al. in his study about the risk and complications of intraoperative epidural steroid injection showed that there is slight increase in risk of infection but it did not reach statistically significant when compared to no use of steroid group. ${ }^{6}$ There was no difference in other complications rate. However, there was significant 
improvement in early postoperative pain among patient with ESI intraoperatively. This study also has shown early beneficial effect on postoperative pain scale and shorter hospital stay but there was no difference in pain scale on long term.

Arirachakaran et al. in his meta-analysis of use of epidural local steroid after discectomy showed decreased consumption of opioids in postoperative phase. ${ }^{8}$ There was no difference in the complications between steroid and placebo group. Devi et al. in his study of 61 patients with intraoperative use of steroid after lumbar discectomy found significant pain relief during postoperative days with less use of opioids but there was no difference in pain on long run and there was no difference in the complication rate. ${ }^{9}$ Ranguis et al. also showed in their study that there is short term benefit of intraoperative ESI in terms of pain and decreased use of analgesics but there is no difference in pain on long run. ${ }^{10}$ Similarly, there is no significant difference in the number of days in the hospital stay. Diaz et al in his randomized controlled trial study showed significant reduction in use of analgesia in the postoperative period but there was no significant difference in the average days of stay in the hospital between the groups who used intraoperative local steroid and who did not. ${ }^{11}$

There was no complications such as infection, recurrence, repeat operation, dural tear or neurological sequelae in either of the group. This may be due to small case number in the current study. Previous studies have shown varying outcome regarding complications such as increased risk of dural tear and infection but there lacks consistent findings in the different studies and meta -analysis.

Limitations of the study: This is retrospective analysis with small sample size and hence need larger sample size to establish the correlation further.

\section{CONCLUSIONS}

Use of local epidural steroid injection intraoperatively after standard discectomy has got beneficial role to reduce the postoperative pain and hospital stay. However, there is no difference in pain scale at 1 week and one year after the operation. There is no added complication with use of ESI intraoperatively.

\section{REFERENCES}

1. Ersayli DT, Gurbet A, Bekar A, Uckunkaya N, Bilgin $H$. Effects of perioperatively administered bupivacaine and bupivacainemethylprednisolone on pain after lumbar discectomy Spine, 31 (19) (2006), pp. 22212226.

2. Grönblad M, Virri J, Tolonen J, et al. A controlled immunohistochemical study of inflammatory cells in disc herniation tissue. Spine, 19 (24) (1994), pp. 2744-2751.

3. Akinduro OO, Miller BA, Haussen, Pradilla G, Ahmad FU. Complications of intraoperative epidural steroid use in lumbar discectomy: a systematic review and meta-analysis. Neurosurg Focus, 39 (4) (2015), p. E12.

4. Cenic A, Kachur E. Lumbar discectomy: a national survey of neurosurgeons and literature review. Can J Neurol Sci, 36 (2) (2009), pp. 196-200.

5. Lowell TD, Errico TJ, Eskenazi MS. Use of epidural steroids after discectomy may predispose to infection. Spine, 25 (4) (2000), pp. 516-519.

6. Diaz RJ, Myles ST, Hurlbert RJ. Evaluation of epidural analgesic paste components in lumbar decompressive surgery: a randomized doubleblind controlled trial. Neurosurgery, 70 (2)
(2012), pp. 414-423.

7. Davis R, Emmons SE. Benefits of epidural methylprednisolone in a unilateral lumbar discectomy: a matched controlled study. J Spinal Disord, 3 (4) (1990), pp. 299-306.

8. Arirachakaran A, Siripaiboonkij M, Pairuchvej S, Setrkraising K, Pruttikul P, Piyasakulkaew C, Kongtharvonskul J. Comparative outcomes of epidural steroids versus placebo after lumbar discectomy in lumbar disc herniation: a systematic review and meta-analysis of randomized controlled trials. Eur J Orthop Surg Traumatol. 2018 Dec;28(8):1589-1599. doi: 10.1007/s00590-018-2229-4.

9. Debi R, Halperin N, Mirovsky Y. Local application of steroids following lumbar discectomy. J Spinal Disord Tech. 2002 Aug;15 (4):273-6.

10. Ranguis SC, Li D, Webster AC: Perioperative epidural steroids for lumbar spine surgery in degenerative spinal disease: a review. J Neurosurg Spine 2010, 13:745-757.

11. Diaz RJ, Myles ST, Hurlbert RJ: Evaluation of epidural analgesic paste component in lumbar decompressive surgery: a randomized doubleblinded controlled trial. Neurosurgery 2012, 70:414-424.

Citation: Pandey S, Bidari S. Retrospective Analysis of Clinical Outcome of Intraoperative Epidural Steroid Injection Versus No Steroid Injection after Standard Lumbosacral Discectomy. JCMS Nepal. 2020; 16(1):33-6. 